ESAIM: PROCEEDINGS AND SURVEYS, September 2014, Vol. 45, p. 189-198

J.-S. Dhersin, Editor

\title{
MODELLING AND ANALYSIS OF PROTEIN AGGREGATION - COMPETING PATHWAYS IN PRION (PRP) POLYMERISATION*
}

\author{
WAFAÂ HAFFAF $^{1}$ AND StÉPhanie PRIGENT ${ }^{2}$
}

\begin{abstract}
Protein aggregation leading to the formation of amyloid fibrils is involved in several neurodegenerative diseases such as prion diseases. To clarify how these fibrils are able to incorporate additional units, prion fibril aggregation and disaggregation kinetics were experimentally studied using Static Light Scattering (SLS). Values that are functions of $\sum_{i>1} i^{2} c_{i}$, with $c_{i}$ being the concentration of fibrils of size $i$, were then measured as a function of time. An initial model, adapted from the Becker-Döring system that considers all fibrils to react similarly is not able to reproduce the observed in vitro behaviour. Our second model involves an additional compartment of fibrils unable to incorporate more prion units. This model leads to kinetic coefficients which are biologically plausible and correctly simulates the first experimental steps for prion aggregation.

Résumé. L'agrégation des protéines conduisant à la formation de fibres amyloïdes est impliquée dans plusieurs maladies neurodégénératives telles que les maladies à prion. Pour clarifier la manière dont les fibres de prion incorporent des unités supplémentaires, les cinétiques d'agrégation et de désagrégation des fibres ont été étudiées expérimentalement (par SLS, "Static Light Diffusion"). Ainsi des valeurs fonction de $\sum_{i \geq 1} i^{2} c_{i}$ avec $c_{i}$ la concentration en fibres de taille $i$ ont été obtenues en fonction du temps. Un premier modèle, adapté du système de Becker-Döring, qui considère que la totalité des fibres réagit de manière similaire ne permet pas de reproduire le comportement observé in vitro. Notre deuxième modèle met en jeu un compartiment additionnel de fibres incapables d'incorporer davantage d'unités de PrP. Celui-ci aboutit à des coefficients cinétiques biologiquement plausibles et simule correctement les premières étapes expérimentales de l'agrégation de prions.
\end{abstract}

\section{INTRODUCTION}

More than twenty diseases, known as amyloid diseases and which include Alzheimer's, Hungtington's and prion diseases are due to the conversion of a protein structure into a misfolded conformation that induces protein aggregation. Recent studies have shown that injections of aggregated proteins involved in Alzheimer's and Parkinson's diseases follow a prion-like mechanism behaviour by a cell-to-cell transmission [6]. However, the exact mechanisms for incorporating prion $(\mathrm{PrP})$ protein to a prion aggregate remain to be clarified. To better

* The authors would like to warmly thank the head of this project, Marie Doumic-Jauffret (INRIA), for her major contribution to this work and Human Rezaei, Davy Martin (INRA) and Joan Torrent Y Mas (INSERM) for initiating this topic, the experimental part and discussions. This research was supported by the ERC Starting Grant SKIPPER ${ }^{A D}$ (fully for S. Prigent and partially for W. Haffaf).

${ }^{1}$ Inria, Paris-Rocquencourt, Domaine de Voluceau, BP105, 78153 Le Chesnay, France; LJLL, Laboratoire Jacques-Louis Lions, Pierre et Marie Curie University, Boite courrier 187, 75252 Paris Cedex 05, France)

${ }^{2}$ Inria; LJLL; INRA, VIM, Domaine de Vilvert, 78352 Jouy-en-Josas cedex, France

(C) EDP Sciences, SMAI 2014 
understand how PrP fibrils can recruit PrP molecules that were not misfolded, we have studied the kinetics of PrP fibril elongation, focusing on polymerisation through the addition of monomer(s) on fibrils. A loss of fibril ability for further polymerisation was experimentally observed after a given number of additions of monomers. Among several hypothetical mechanisms and according to different experiments [7], a hypothetical occurrence of a structural defect on fibrils could explain this loss of the ability to polymerise.

Relying on the iterative modeling process, we have written two models for the simulation of prion polymerisation/depolymerisation. The first model, the basic one, led us to the Becker-Döring system for phase transition phenomena. Nevertheless, this model was unable to reproduce the loss of fibril ability for polymerisation. The second model involves the formation of fibrils with a structural defect preventing them from any further polymerisation. This model, with suitable parameter estimations, numerically reproduces part of the empirically observed curves of prion fibril kinetics.

\section{BiologicAl EXPERIMENTS}

To clarify prion aggregation mechanisms, polymerisation and depolymerisation of prion fibrils were studied in vitro as a function of time, starting from preformed fibrils. These experiments were set up and performed by the team of Dr. H. Rezaei, Dr. D. Martin and Dr. J. Torrent Y Mas from INRA (Jouy-en-Josas, France). The kinetics were followed by SLS (Static Light Scattering) performed on a cuvette containing PrP fibrils in an aqueous buffer solution. SLS measures $\alpha\left(\sum_{i \geq 1} i^{2} \mathrm{c}_{i}\right)+\beta$, with $\mathrm{c}_{i}$ being the concentration of polymers of size $\mathrm{i}$, and $\alpha$ and $\beta$ being parameters that are constant during each experiment. Because the experimental sample is a heterogeneous mixture of polymers of various sizes, this technique does not give access to the concentration of polymers of a precise size. To clarify the mechanisms involved in fibril growth once fibrils have formed, i.e. how additional monomers are recruited by fibrils, the experimental approach consisted in successive additions of monomers on fibrils (Figure 1). At time 0 a first addition of monomers was performed on the fibrils. The following additions of monomers were made once the SLS measurement had reached a quasi plateau. After a certain number of additions of human PrP monomers on human PrP fibrils, the SLS signal did not increase anyfurther. However, the SLS signal was increased by a further addition of mutant PrP monomers that differ from human PrP monomers in their structure. This observation and other experiments indicate that fibrils growth probably does not stop simply because the fibril has reached a certain size [7].

Complementary experiments using another technique (spectrophotometry) were also performed to get a crude estimate of the concentration of free monomers at the end of the first two plateaux; these indicated that only a small percentage of initial monomers was incorporated onto fibrils.

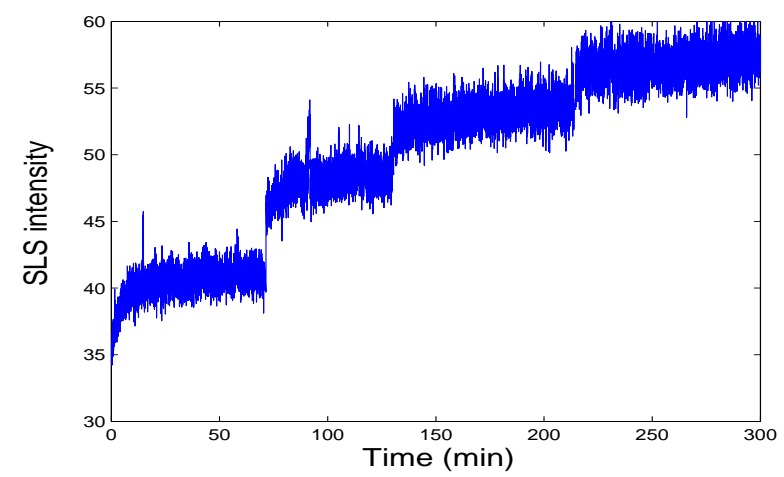

FiguRE 1. SLS experimental data of successive additions of monomers on PrP human fibrils 


\section{BASIC MODEL FOR FIBRIL-MONOMER REACTION}

We start this modeling process by considering only classic prion fibrils with their basic reactions, which results in the following model.

\subsection{Basic model}

An $i$-sized polymer can gain a free monomer to become an $(i+1)$-sized polymer. This reaction is called polymerisation, it occurs with a non-negative size-dependant rate $\mathrm{k}_{\mathrm{on}_{i}}$.

An $i$-sized polymer can also release a monomer, giving rise to a smaller polymer, of size $i-1$, and a free monomer. This reaction is named depolymerisation. It occurs with a non-negative size-dependant rate, $\mathrm{k}_{\mathrm{dep}_{i}}$. Denoting by $\mathrm{c}_{i}$ the concentration in polymers of size $i$, with $i=1,2, \ldots$, we get the following scheme of reactions:

$$
\begin{aligned}
\mathrm{c}_{i}+\mathrm{c}_{1} \stackrel{\mathrm{k}_{\mathrm{on}_{i}}}{\longrightarrow} \mathrm{c}_{i+1}, & i \geq 1, \\
\mathrm{c}_{i} \underset{\mathrm{k}_{\mathrm{dep}_{i}}}{\longrightarrow} \mathrm{c}_{i-1}+\mathrm{c}_{1}, & i \geq 2 .
\end{aligned}
$$

In terms of equations, it gives the well-known Becker-Döring system [2] :

$$
\left\{\begin{array}{l}
\frac{d \mathrm{c}_{i}}{d t}=-\mathrm{k}_{\mathrm{On}_{i}} \mathrm{c}_{1} \mathrm{c}_{i}+\mathrm{k}_{\mathrm{On}_{i-1}} \mathrm{c}_{1} \mathrm{c}_{i-1}-\mathrm{k}_{\mathrm{dep}_{i}} \mathrm{c}_{i}+\mathrm{k}_{\mathrm{dep}_{i+1}} \mathrm{c}_{i+1} \quad i \geq 2 \\
\frac{d \mathrm{c}_{1}}{d t}=-\sum_{i=2}^{\infty}\left(\mathrm{k}_{\mathrm{on}_{i}} \mathrm{c}_{1} \mathrm{c}_{i}-\mathrm{k}_{\mathrm{dep}_{i+1}} \mathrm{c}_{i+1}\right)-2\left(\mathrm{k}_{\mathrm{on}_{1}} \mathrm{c}_{1}^{2}-\mathrm{k}_{\mathrm{dep}_{2}} \mathrm{c}_{2}\right) .
\end{array}\right.
$$

This is obtained directly from the schemes reactions, using the law of mass action several times. One can notice that a particular equation is needed for the variation of concentration of 1-sized particules that are called monomers. This is due to their interaction in all the processes.

A detailed qualitative study of this system was carried out in several articles, such as [1], [3], and [5]. In [1], the authors give theorems of existence, uniqueness, continuous dependence of initial data and the fundamental mass conservation property:

$$
\mathrm{c}_{1}(t)=\sum_{i=1}^{\infty}\left(i \mathrm{c}_{i}(0)\right)-\sum_{i=2}^{\infty}\left(i \mathrm{c}_{i}(t)\right) .
$$

For new fibrils to be created through the reaction

$$
\mathrm{c}_{1}+\mathrm{c}_{1} \stackrel{\mathrm{k}_{\mathrm{on}}}{\longrightarrow} \mathrm{c}_{2}
$$

biogically requires a greater time than the time-scale of the experiments reported here. This was deduced through a control experiment where a constant signal was observed when using only monomers in the same duration (300min). Therefore, the coefficient $\mathrm{k}_{\mathrm{on}_{1}}$ is assumed to be null $\left(\mathrm{k}_{\mathrm{on}_{1}}=0\right)$.

\subsection{Simplified system}

To gain further qualitative insight into the dynamics of these equations and a concrete idea about the order of magnitude of the kinetics coefficients $\mathrm{k}_{\mathrm{on}}$ and $\mathrm{k}_{\mathrm{dep}}$, we initially consider a simplified system (which we will make more complex afterwards). This involves a summation of all the equations of the infinite Becker-Döring system (1) over all sizes. The simplification is the assumption we make on the coefficients $k_{\text {on }}$ and $k_{\text {dep }}$ by considering them to be constant. As all the fibrils are almost the same size, this assumption is justified. Moreover, we consider a time-scale where the concentration in dimers, $\mathrm{c}_{2}$, is negligible. This results in the following simplified system : 


$$
\left\{\begin{array}{l}
\frac{d \mathrm{P}}{d t}=0 \\
\frac{d \mathrm{M}}{d t}=\mathrm{k}_{\mathrm{on}} \mathrm{c}_{1} \mathrm{P}-\mathrm{k}_{\mathrm{dep}} \mathrm{P} \\
\frac{d \mathrm{c}_{1}}{d t}=-\mathrm{k}_{\mathrm{on}} \mathrm{c}_{1} \mathrm{P}+\mathrm{k}_{\mathrm{dep}} \mathrm{P}
\end{array}\right.
$$

where $\mathrm{P}=\sum_{i>2} \mathrm{c}_{i}(t)$ represents the total concentration of fibrils summed over all sizes $i \geq 2$,

$\mathrm{M}=\sum_{i \geq 2} i \mathrm{c}_{i}(t)$ represents the total mass of fibrils summed over all sizes $i \geq 2$,

$\mathrm{c}_{1}$ the concentration of monomers.

The total mass conservation is then obvious.

The equation of the second order moment (measured data) variation is also simplified into :

$$
\frac{d \mathrm{M}_{2}^{\text {measured }}}{d t}=2 \mathrm{M}\left(\mathrm{k}_{\mathrm{on}} \mathrm{c}_{1}-\mathrm{k}_{\mathrm{dep}}\right)+2 \mathrm{k}_{\mathrm{dep}} \mathrm{P}
$$

and once the closed simplified system (2) has been solved, an analytical expression for $\mathrm{M}_{2}^{\text {measured }}$ can be easily deduced. Indeed, after integrating (2) we get :

$$
\left\{\begin{array}{l}
\mathrm{P}=\mathrm{P}^{i n} \\
\mathrm{M}(t)=\mathrm{M}^{i n}-\mathrm{k}_{\mathrm{on}}\left(\mathrm{c}_{1}^{i n}-\mathrm{c}_{1}^{e q}\right) \mathrm{e}^{-\mathrm{k}_{\mathrm{on}} \mathrm{P}^{\mathrm{in}} \mathrm{t}} \mathrm{P}^{\mathrm{in}}+\left(\mathrm{c}_{1}^{\mathrm{in}}-\mathrm{c}_{1}^{\mathrm{eq}}\right) \\
\mathrm{c}_{1}(t)=\left(\mathrm{c}_{1}^{i n}-\mathrm{c}_{1}^{e q}\right) \mathrm{e}^{-\mathrm{k}_{\mathrm{on}} \mathrm{P}^{\mathrm{in}} \mathrm{t}}+\mathrm{c}_{1}^{\mathrm{eq}}
\end{array}\right.
$$

where $\mathrm{P}^{i n}=\mathrm{P}(0)$ represents the initial total concentration of polymers and $\mathrm{M}^{\text {in }}=\mathrm{M}(0)$ their initial total mass, $c_{1}^{i n}=c_{1}(t=0)$ the initial concentration of monomers and $c_{1}^{e q}=\frac{\mathrm{k}_{\mathrm{dep}}}{\mathrm{k}_{\mathrm{on}}}$ the concentration of monomers at equilibrium state (when $\frac{d \mathrm{c}_{1}}{d t}=0$, see $(2)$ ).

Thus,

$$
\mathrm{M}_{2}^{\text {measured }}=A+B\left(e^{-\mathrm{k}_{\mathrm{on}} \mathrm{P}^{i n} t}-1\right)+C\left(e^{-2 \mathrm{k}_{\mathrm{on}} \mathrm{P}^{i n} t}-1\right)+2 \mathrm{k}_{\mathrm{dep}} \mathrm{P}^{i n} t
$$

with $A=\mathrm{M}_{2}^{i n}, B=-\frac{2}{\mathrm{P}^{i n}}\left(\mathrm{M}^{i n}+\mathrm{c}_{1}^{i n}-\mathrm{c}_{1}^{e q}\right)\left(\mathrm{c}_{1}^{i n}-\mathrm{c}_{1}^{e q}\right)$ and $C=\frac{\left(\mathrm{c}_{1}^{e q}-\mathrm{c}_{1}^{i n}\right)^{2}}{\mathrm{P}^{i n}}$.

One can notice from the mass expression $\mathrm{M}(t)$ above that we need to assume $\mathrm{c}_{1}^{e q}=\frac{\mathrm{k}_{\mathrm{dep}}}{\mathrm{k}_{\mathrm{on}}} \leq \mathrm{c}_{1}^{\text {in }}+\mathrm{M}^{i n}$, else neglecting $c_{2}$ in (1) is not valid and $\mathrm{M}(t)$ defined by (3) would become negative for large time.

The next step is then to estimate the parameters $\mathrm{k}_{\mathrm{on}}, \mathrm{k}_{\mathrm{dep}}, \alpha$ and $\beta$ using the experimental data of $S L S$ with $S L S=\alpha \mathrm{M}_{2}^{\text {measured }}+\beta$.

We reformulate this inverse problem into the minimisation of the corresponding least squares criterion

$$
J\left(\mathrm{k}_{\mathrm{on}}, \mathrm{k}_{\mathrm{dep}}, \alpha, \beta\right)=\sum_{i=1}^{n}\left|\left(\alpha \mathrm{M}_{2}^{\text {measured }}\left(t_{i} ; \mathrm{k}_{\mathrm{on}}, \mathrm{k}_{\mathrm{dep}}\right)+\beta\right)-S L S\left(t_{i}\right)\right|^{2}
$$

The uniqueness of the solution is, as for most non-linear inverse problems, non-trivial. This is essentially due to the non-convexity of the cost functional $J$.

This minimisation allows us to get a satisfactory estimation for the first step of the experiments (Figure 2), but only for the first addition of monomers. At each new addition of monomers to the solute, fibrils once again start polymerising, consuming monomers. Despite the fact that the consumption of monomers is lower than in 

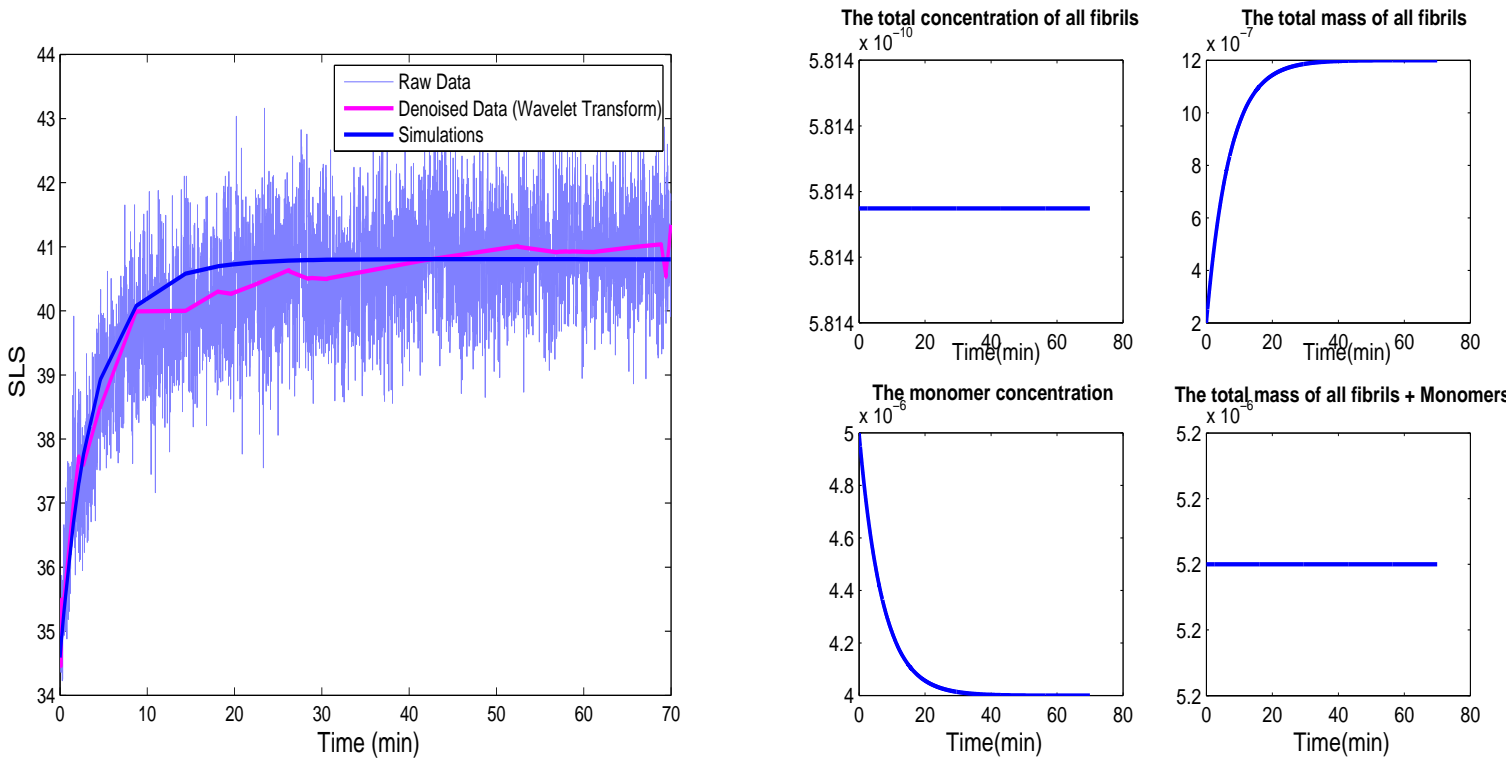

FiguRE 2. Simulation of the first addition of monomers. (Quantities are in $m o l . L^{-1}$.)

the first step ( due to volume dilution in the cuvette), the gap between two successive additions is higher and higher (Figure 3). This is due to the $i^{2}$ term in the simulated quantity $\alpha\left(\sum_{i \geq 1}^{n} i^{2} \mathrm{c}_{i}\right)+\beta$ (Figure 3 ).
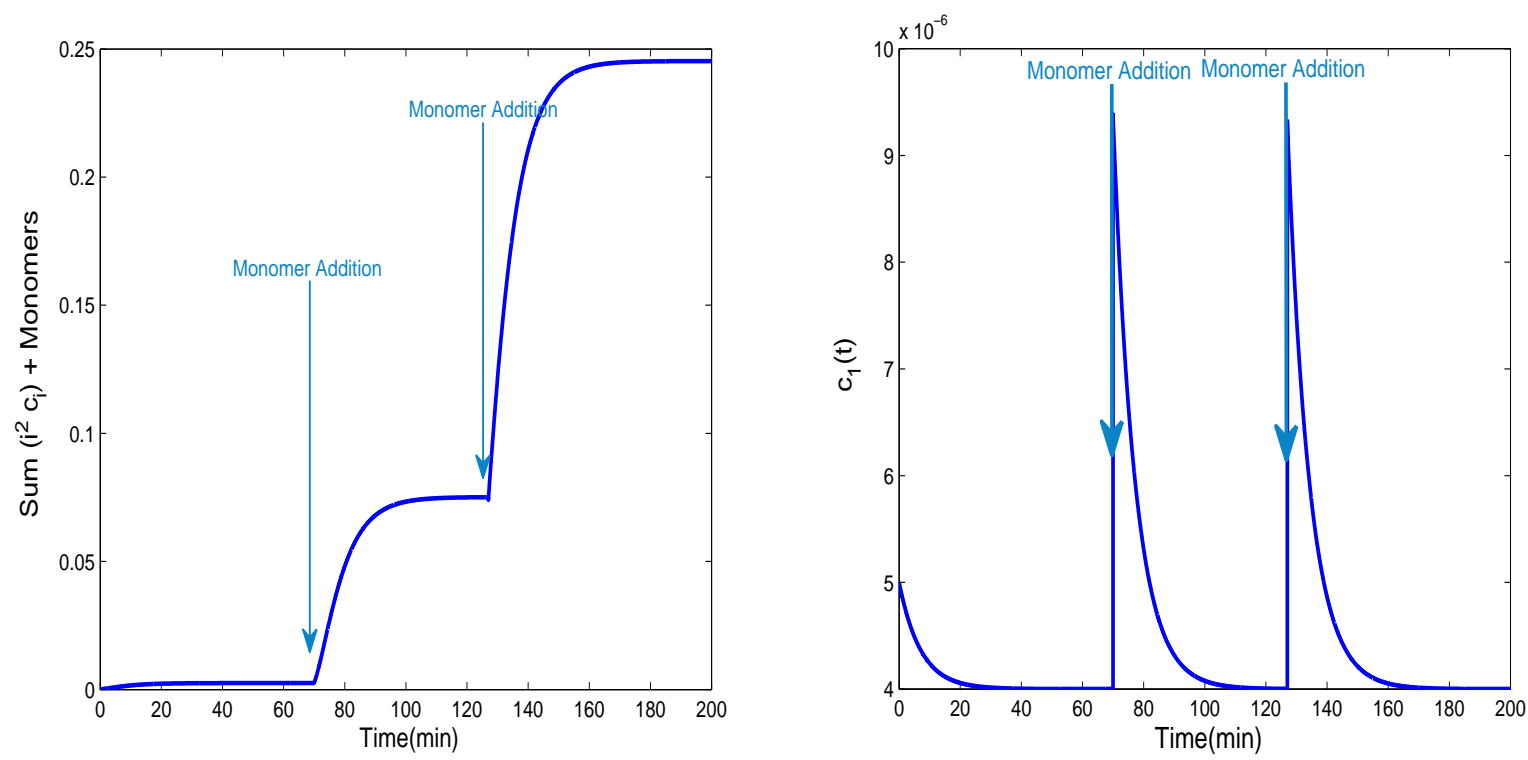

FIGURE 3. Simulation of the first three additions of monomers with solute-dilution in the second and third ones. 
We conclude here that a stop pathway is needed to slow down the polymerisation of fibrils and the growth of their average size $i$ and, hence, $i^{2}$.

\section{TWO-COMPARTMENT MODEL}

\subsection{Discrete model}

To force the polymerisation to stop, we set the hypothesis of creating a different fibril that will no longer be able to polymerise due to a defect in its structure.

This defective fibril would be the result of the polymerisation of a classic fibril with a polymerisation rate $\mathrm{k}_{\mathrm{on}}^{\mathrm{m}}$. We denote by $\mathrm{c}_{i}^{\mathrm{m}}$ the concentration of the defective fibrils of size $i$. The reactions are now:

$$
\begin{aligned}
& \mathrm{c}_{i}+\mathrm{c}_{1} \stackrel{\mathrm{k}_{\mathrm{on}_{i}}}{\longrightarrow} \mathrm{c}_{i+1}, \quad i \geq 1, \\
& \mathrm{c}_{i} \underset{\mathrm{k}_{\mathrm{dep}_{i}}}{\longrightarrow} \mathrm{c}_{i-1}+\mathrm{c}_{1}, \quad i \geq 2, \\
& \mathrm{c}_{i}+\mathrm{c}_{1} \stackrel{\mathrm{k}_{\mathrm{on}_{i}}^{\mathrm{m}}}{\longrightarrow} \mathrm{c}_{i+1}^{\mathrm{m}} \nrightarrow, \quad i \geq 2, \\
& \mathrm{c}_{i}^{\mathrm{m}} \underset{\mathrm{k}_{\mathrm{dep}_{i}}^{\mathrm{m}}}{\longrightarrow} \mathrm{c}_{i-1}+\mathrm{c}_{1}, \quad i \geq 3 .
\end{aligned}
$$

Which can be translated into the following ordinary differential equations system :

$$
\left\{\begin{aligned}
& \frac{d \mathrm{c}_{i}}{d t}=-\mathrm{k}_{\mathrm{On}_{i}} \mathrm{c}_{1} \mathrm{c}_{i}+\mathrm{k}_{\mathrm{On}_{i-1}} \mathrm{c}_{1} \mathrm{c}_{i-1}-\mathrm{k}_{\mathrm{On}_{i}}^{\mathrm{m}} \mathrm{c}_{1} \mathrm{c}_{i}-\mathrm{k}_{\mathrm{dep}_{i}} \mathrm{c}_{i} \\
&+\mathrm{k}_{\mathrm{dep}_{i+1}} \mathrm{c}_{i+1}+\mathrm{k}_{\mathrm{dep}_{i+1}}^{\mathrm{m}} \mathrm{c}_{i+1}^{\mathrm{m}}, \quad i \geq 2 \\
& \frac{d \mathrm{c}_{i}^{\mathrm{m}}}{d t}=\mathrm{k}_{\mathrm{On}_{i-1}}^{\mathrm{m}} \mathrm{c}_{1} \mathrm{c}_{i-1}-\mathrm{k}_{\mathrm{dep}_{i}}^{\mathrm{m}} \mathrm{c}_{i}^{\mathrm{m}}, \quad i \geq 3 \\
& \frac{d \mathrm{c}_{1}}{d t}=-\sum_{i=2}^{\infty} \mathrm{k}_{\mathrm{On}_{i}} \mathrm{c}_{1} \mathrm{c}_{i}-\sum_{i=2}^{\infty} \mathrm{k}_{\mathrm{On}_{i}}^{\mathrm{m}} \mathrm{c}_{1} \mathrm{c}_{i}+\sum_{i=2}^{\infty} \mathrm{k}_{\mathrm{dep}_{i}} \mathrm{c}_{i}+\sum_{i=3}^{\infty} \mathrm{k}_{\mathrm{dep}_{i}}^{\mathrm{m}} \mathrm{c}_{i}^{\mathrm{m}} \\
&-2\left(\mathrm{k}_{\mathrm{On}_{1}} \mathrm{c}_{1}^{2}-\mathrm{k}_{\mathrm{dep}_{2}} \mathrm{c}_{2}\right)
\end{aligned}\right.
$$

\subsection{The two-compartment simplified system}

We denote by $\mathrm{P}^{\mathrm{m}}=\sum_{i \geq 3} \mathrm{c}_{i}^{\mathrm{m}}(t)$ the total concentration of defective polymers.

$$
\mathrm{M}^{\mathrm{m}}=\sum_{i \geq 3}^{i \geq 3} i \mathrm{c}_{i}^{\mathrm{m}}(t) \text { the total mass of defective polymers. }
$$

Summing once again over all sizes, we obtain the following system :

$$
\left\{\begin{array}{l}
\frac{d \mathrm{P}}{d t}=-\mathrm{k}_{\mathrm{on}}^{\mathrm{m}} \mathrm{c}_{1} \mathrm{P}+\mathrm{k}_{\mathrm{dep}}^{\mathrm{m}} \mathrm{P}^{\mathrm{m}} \\
\frac{d \mathrm{P}^{\mathrm{m}}}{d t}=\mathrm{k}_{\mathrm{on}}^{\mathrm{m}} \mathrm{c}_{1} \mathrm{P}-\mathrm{k}_{\mathrm{dep}}^{\mathrm{m}} \mathrm{P}^{\mathrm{m}} \\
\frac{d \mathrm{M}}{d t}=\mathrm{k}_{\mathrm{on}} \mathrm{c}_{1} \mathrm{P}-\mathrm{k}_{\mathrm{on}}^{\mathrm{m}} \mathrm{c}_{1} \mathrm{M}-\mathrm{k}_{\mathrm{dep}} \mathrm{P}+\mathrm{k}_{\mathrm{dep}}^{\mathrm{m}}\left(\mathrm{M}^{\mathrm{m}}-\mathrm{P}^{\mathrm{m}}\right) \\
\frac{d \mathrm{M}^{\mathrm{m}}}{d t}=\mathrm{k}_{\mathrm{on}}^{\mathrm{m}} \mathrm{c}_{1}(\mathrm{P}+\mathrm{M})-\mathrm{k}_{\mathrm{dep}}^{\mathrm{m}} \mathrm{M}^{\mathrm{m}} \\
\frac{d \mathrm{c}_{1}}{d t}=-\mathrm{k}_{\mathrm{on}} \mathrm{c}_{1} \mathrm{P}-\mathrm{k}_{\mathrm{on}}^{\mathrm{m}} \mathrm{c}_{1} \mathrm{P}+\mathrm{k}_{\mathrm{dep}} \mathrm{P}+\mathrm{k}_{\mathrm{dep}}^{\mathrm{m}} \mathrm{P}^{\mathrm{m}}
\end{array}\right.
$$


and the measured data :

$$
\frac{d \mathrm{M}_{2}^{\text {measured }}}{d t}=2 \mathrm{c}_{1} \mathrm{M}\left(\mathrm{k}_{\mathrm{on}}+\mathrm{k}_{\mathrm{on}}^{\mathrm{m}}\right)+2 \mathrm{k}_{\mathrm{dep}}(\mathrm{P}-\mathrm{M})+2 \mathrm{k}_{\mathrm{dep}}^{\mathrm{m}}\left(\mathrm{P}^{\mathrm{m}}-\mathrm{M}^{\mathrm{m}}\right)
$$

In order to fit the experimental data for the first addition of monomers, kinetic parameters for the twocompartment model were obtained as follows.

We suppose the fibrils to be exclusively composed of classic fibrils at time 0 , and that defective fibrils are absent. We start with a simplified view of the system to obtain certain values of kinetic constants able to fit the data. For this reason, we consider that at the beginning of the experiment the system is nearly a model with only one compartment.

For the basic model, we can deduce from (3) that after a certain time denoted $t^{e q}$ (for equilibrium time), the quantity $\left(\mathrm{c}_{1}^{i n}-\mathrm{c}_{1}^{e q}\right) \mathrm{e}^{-\mathrm{k}_{\text {on }} \mathrm{P}^{\mathrm{in}} \mathrm{t}^{\mathrm{eq}}}$ is negligible when compared to $\mathrm{c}_{1}^{e q}$. We consider $e^{-\mathrm{k}_{\mathrm{on}} \mathrm{P}^{i n} t^{e q}}$ in the $10^{-1}$ range, i.e. $-\mathrm{k}_{\mathrm{on}} \mathrm{P}^{i n} t^{e q} \simeq-2$. Therefore, for the basic model, we have approximately :

$$
\begin{array}{r}
\mathrm{k}_{\mathrm{on}} \mathrm{P}^{i n} t^{e q}=2 \\
\Rightarrow \quad \mathrm{k}_{\mathrm{on}}=\frac{2}{\mathrm{P}^{i n} t^{e q}}
\end{array}
$$

By analogy with the basic model, after replacing $\mathrm{P}^{i n}\left(\mathrm{P}\right.$ initial) by $\mathrm{P}^{e q}$ ( $\mathrm{P}$ of classic fibrils at equilibrium state) in the $\mathrm{k}_{\mathrm{on}}$ formula $(6)$ from the basic model, we can obtain certain values of $\mathrm{k}_{\mathrm{on}}$ and $\mathrm{k}_{\mathrm{dep}}$, for the two-compartment model, able to fit the first minutes. To calculate $\mathrm{k}_{\mathrm{on}}$, we use a fixed value for $t^{e q}=8$ min (chosen from the minimal time where the experimental SLS slope reaches nearly 0$)$.

For $\mathrm{k}_{\mathrm{dep}}$, with $\mathrm{k}_{\mathrm{dep}}=\mathrm{k}_{\mathrm{on}} \mathrm{c}_{1}^{e q}$, we use $\frac{75}{100} \mathrm{c}_{1}^{i n} \leq \mathrm{c}_{1}^{e q} \leq \frac{96}{100} \mathrm{c}_{1}^{i n}$ (from experimentally estimated values of $\mathrm{c}_{1}$ ) where $c_{1}^{i n}=5 \cdot 10^{-6}$ mol. $L^{-1}$.

In this way, during the first minutes, the concentration of consumed $c_{1}$ is modulated by the classic fibrils (more exactly by the ratio $\mathrm{k}_{\mathrm{dep}} / \mathrm{k}_{\mathrm{on}}$ ) whereas any effect of the few defective fibrils on the concentration of monomers can be ignored. This analogy with the 'basic model' offers access to a part of the sets of plausible kinetic constants able to fit the first addition of monomers.

Once $\mathrm{k}_{\mathrm{on}}$ and $\mathrm{k}_{\mathrm{dep}}$ were calculated as functions of $\mathrm{P}^{\mathrm{m}}{ }^{e q}$ (the concentration of defective fibrils at equilibrium state, with a value from 0 to $100 \%$ of $\mathrm{P}^{i n}$ ), the kinetic constants $\mathrm{k}_{\mathrm{dep}}^{\mathrm{m}}$ and then $\mathrm{k}_{\mathrm{on}}^{\mathrm{m}}$ for defective fibrils were deduced. $\mathrm{k}_{\mathrm{dep}}^{\mathrm{m}}$ was got by a small inverse problem (using the Matlab routine fminsearch) from a broad range of potential $\mathrm{k}_{\mathrm{dep}}^{\mathrm{m}}$ values $\left(0 \leq \mathrm{k}_{\mathrm{dep}}^{\mathrm{m}} \leq 10^{4}\right)$.

$\mathrm{k}_{\mathrm{on}}^{\mathrm{m}}$ was deduced from the equilibrium state between classic and defective fibrils:

$$
\begin{aligned}
& \frac{d \mathrm{P}}{d t}=\frac{d \mathrm{P}^{\mathrm{m}}}{d t}=0 \\
& \Rightarrow \mathrm{k}_{\mathrm{on}}^{\mathrm{m}}=\frac{\mathrm{k}_{\mathrm{dep}}^{\mathrm{m}} \mathrm{P}^{\mathrm{m}}}{\mathrm{c}_{1} \mathrm{P}}
\end{aligned} \quad \Rightarrow-\mathrm{k}_{\mathrm{on}}^{\mathrm{m}} \mathrm{c}_{1} \mathrm{P}+\mathrm{k}_{\mathrm{dep}}^{\mathrm{m}} \mathrm{P}^{\mathrm{m}}=0
$$

Table 1 presents calculated values for the kinetic parameters allowing us to reproduce the SLS signal for the first addition of monomers. Each percentage of defective fibrils, from 0 up to $100 \%$ of the initial concentration of total fibrils, $\mathrm{P}^{i n}$, allows the SLS signal to be mimicked for the first addition of monomers; this was accompanied by a broad range of $\mathrm{k}_{\mathrm{on}}^{\mathrm{m}}\left(0\right.$ to $3 \cdot 10^{12}$ mol. $\left.L^{-1} \cdot \mathrm{min}^{-1}\right)$ and of $\mathrm{k}_{\mathrm{dep}}^{\mathrm{m}}\left(0\right.$ to $\left.1.10^{4} \mathrm{~min}^{-1}\right)$.

The next step is to fit the effect of a second addition of monomers on the SLS signal once this signal has reached a plateau. To reach this goal, let us focus on and try to simplify the term representative of the SLS signal, $\alpha \mathrm{M}_{2}^{\text {measured }}+\beta$ (with $\alpha$ and $\beta$ being constant as previously mentioned) 


\begin{tabular}{|c|c|c|c|c|}
\hline $\begin{array}{c}P_{m}{ }^{e q} \\
\left(\% \text { of } P_{\text {total }}\right)\end{array}$ & $k_{\text {on }}$ & $\mathbf{k}_{\text {dep }}$ & $\mathbf{k}_{\text {on }}{ }^{m}$ & $\mathbf{k}_{\text {dep }}{ }^{m}$ \\
\hline 0 & $4.10^{8}$ & $2.10^{3}$ & 0 & 0 \\
\hline 0.5 & $4.10^{8}$ & $2.10^{3}$ & $1.10^{1}$ to $1.10^{7}$ & $8.10^{-3}$ to $1.10^{4}$ \\
\hline 10 & $5.10^{8}$ & $2.10^{3}$ & $2.10^{3}$ & $6.10^{-2}$ \\
\hline 30 & $6.10^{8}$ & $2.10^{3}$ & $1.10^{7}$ to $1.10^{9}$ & $1.10^{2}$ to $1.10^{4}$ \\
\hline 50 & $9.10^{8}$ & $3.10^{3}$ & $2.10^{7}$ & $1.10^{2}$ \\
\hline 80 & $2.10^{9}$ & $8.10^{3}$ & $1.10^{8}$ & $1.10^{2}$ \\
\hline 95 & $9.10^{9}$ & $3.10^{4}$ & $3.10^{7}$ & 10 \\
\hline 99 & $4.10^{10}$ & $2.10^{5}$ & $3.10^{7}$ to $1.10^{9}$ & 1 to 10 \\
\hline 99.99 & $4.10^{12}$ & $2.10^{7}$ & $3.10^{9}$ to $3.10^{12}$ & 1 to $1.10^{3}$ \\
\hline 0 to $100 \%$ & $4.10^{8}$ to $4.10^{12}$ & $2.10^{3}$ to $2.10^{7}$ & 0 to $3.10^{12}$ & 0 to $1.10^{4}$ \\
\hline
\end{tabular}

TABLE 1 . Kinetic constants $\left(\mathrm{k}_{\mathrm{on}}, \mathrm{k}_{\mathrm{on}}^{\mathrm{m}}, \mathrm{k}_{\mathrm{dep}}\right.$ and $\left.\mathrm{k}_{\mathrm{dep}}^{\mathrm{m}}\right)$ able to fit the first addition of monomers for the two-compartment model. $\mathrm{k}_{\mathrm{on}}$ and $\mathrm{k}_{\mathrm{dep}}$ are obtained by analogy with the basic model, $\mathrm{k}_{\mathrm{on}}^{\mathrm{m}}$ and $\mathrm{k}_{\mathrm{dep}}^{\mathrm{m}}$, as a function of $\mathrm{P}^{\mathrm{m}^{e q}}$ (total concentration of defective fibrils at equilibrium state), through an inverse problem. Various values of $\mathrm{P}^{\mathrm{m}^{e q}}$ were used in order to test a wide range of initializations of the minimization algorithm. The lack of identifiability of the inverse problem leads to several sets of kinetic constants which are reported above. The last line summarizes the values for the whole range of $\mathrm{P}^{\mathrm{m}^{e q}}$.

whose variation is given in Equation (5):

$$
\frac{d \mathrm{M}_{2}^{\text {measured }}}{d t}=2 \mathrm{c}_{1} \mathrm{M}\left(\mathrm{k}_{\mathrm{on}}+\mathrm{k}_{\mathrm{on}}^{\mathrm{m}}\right)+2 \mathrm{k}_{\mathrm{dep}}(\mathrm{P}-\mathrm{M})+2 \mathrm{k}_{\mathrm{dep}}^{\mathrm{m}}\left(\mathrm{P}^{\mathrm{m}}-\mathrm{M}^{\mathrm{m}}\right)
$$

From this equation, as logically expected, the positive part depends on the polymerisation constants $\left(\mathrm{k}_{\mathrm{on}}\right.$ and $\mathrm{k}_{\mathrm{on}}^{\mathrm{m}}$ ) and the negative parts on the depolymerisation constants $\left(\mathrm{k}_{\mathrm{dep}}\right.$ and $\mathrm{k}_{\mathrm{dep}}^{\mathrm{m}}$ ), the subtraction between fibril concentration and fibril mass (P- M) rendering these parts negative.

It was experimentally observed that with a given number of successive additions, the SLS signal almost stops increasing (Figure 1). We thus can postulate that nearly $100 \%$ of fibrils became defective at that moment and it might indicate a high stability of defective fibrils i.e. $\mathrm{k}_{\mathrm{dep}}^{\mathrm{m}} \approx 0$. However, even if such an assumption $\mathrm{k}_{\mathrm{dep}}^{\mathrm{m}} \approx 0$ could be verified, neglecting the term $2 \mathrm{k}_{\mathrm{dep}}^{\mathrm{m}}\left(\mathrm{P}^{\mathrm{m}}-\mathrm{M}^{\mathrm{m}}\right)$ in Equation (5) is not possible: indeed the very low values of $\mathrm{c}_{1}\left(5.10^{-6}\right), \mathrm{P}\left(0 \leq \mathrm{P} \leq 6.67 .10^{-10}\right)$ and $\mathrm{M}\left(0 \leq \mathrm{M} \leq 2.10^{-5}\right.$ roughly $)$ and the potential numerical values for $\mathrm{k}_{\mathrm{on}}, \mathrm{k}_{\mathrm{on}}^{\mathrm{m}}$ and $\mathrm{k}_{\mathrm{dep}}$ easily turn the three terms of Equation (5) into values of similar or almost similar numerical ranges.

To fit the second addition of monomers, we tested all the previously found sets of kinetic constants $\left(\mathrm{k}_{\mathrm{on}}, \mathrm{k}_{\mathrm{on}}^{\mathrm{m}}\right.$, $\mathrm{k}_{\mathrm{dep}}$ and $\mathrm{k}_{\mathrm{dep}}^{\mathrm{m}}$ ) that closely mimicked the first addition of monomers. After adjusting these values for a satisfactory curve-fitting of the height of the second addition of monomers, one set of values was able to reproduce the first addition and the height of the second one (Figure 4, left panel). It is therefore confirmed that, in contrast to the basic model, the two-compartment model makes it possible to mimick the increase in the SLS signal by a second addition of monomers. However, the beginning of the slope of the second addition was not satisfactory, nor was the height for the third and subsequent additions of monomers (Figure 4, right panel). The fact that 

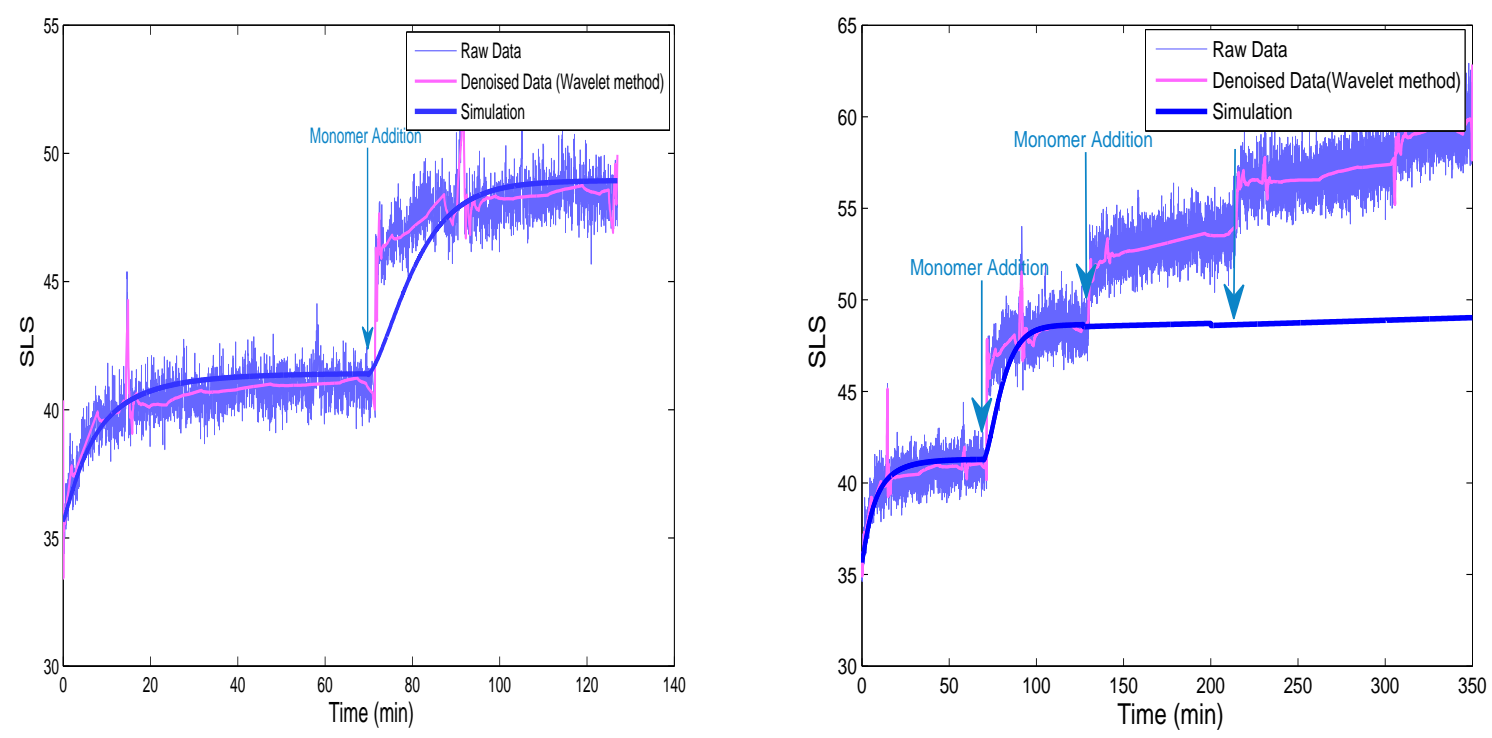

Figure 4. Curve fitting for two (left panel) and four (right panel) successive additions of monomers, with the "two-compartment model" (using $\mathrm{k}_{\mathrm{on}}=3.5 \cdot 10^{8} \mathrm{~mol}^{-L^{-1}} \cdot \mathrm{min}^{-1} ; \mathrm{k}_{\mathrm{dep}}=$ $1 \cdot 6 \cdot 10^{3} \mathrm{~min}^{-1} ; \mathrm{k}_{\mathrm{on}}^{\mathrm{m}}=1 \cdot 7 \cdot 10^{4}$ mol. $\mathrm{L}^{-1} \cdot \mathrm{min}^{-1}$ and $\mathrm{k}_{\mathrm{dep}}^{\mathrm{m}}=1 \cdot 10^{-6} \mathrm{~min}^{-1}$ )

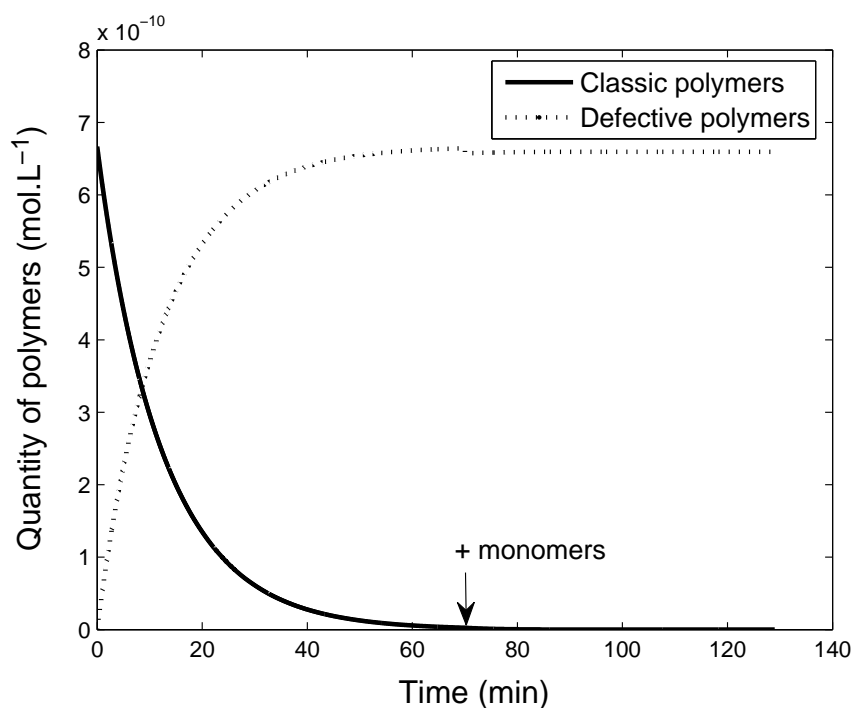

Figure 5. Quantity of defective fibrils as a function of time for the set of kinetic coeffficients able to fit the heights of the two first additions of monomers (i.e. set of values used in Figure 5: $\mathrm{k}_{\mathrm{on}}=3 \cdot 5 \cdot 10^{8} \mathrm{~mol} \cdot \mathrm{L}^{-1} \cdot \mathrm{min}^{-1}, \mathrm{k}_{\mathrm{dep}}=1 \cdot 6 \cdot 10^{3} \mathrm{~min}^{-1}, \mathrm{k}_{\mathrm{on}}^{\mathrm{m}}=1 \cdot 7 \cdot 10^{4} \mathrm{~mol} L^{-1} \cdot \mathrm{min}^{-1}$ and $\mathrm{k}_{\mathrm{dep}}^{\mathrm{m}}=$ $\left.1.10^{-6} \mathrm{~min}^{-1}\right)$ 
the third addition did not make it possible to increase sufficiently the simulated signal can be explained by the low $\mathrm{k}_{\mathrm{dep}}^{\mathrm{m}}$ and the high percentage of modified fibrils (Figure 5). Regarding the slopes, the contribution of the different biological parameters will be mathematically studied in a future sensitivity problem. This study will

enable us, for instance, to confirm (or infirm) that a high ratio $\frac{\mathrm{k}_{\mathrm{on}}^{\mathrm{m}}}{\mathrm{k}_{\mathrm{dep}}^{\mathrm{m}}}$ compared to the ratio $\frac{\mathrm{k}_{\mathrm{on}}}{\mathrm{k}_{\mathrm{dep}}}$ could decrease the slopes (as the formation of defective fibrils prevents a further increase in its size).

This work has shown that the basic model with only one type of fibril could not explain the observed kinetic behavior of prion fibrils. Therefore, a model with at least two compartments is necessary. Biologically speaking, this could be the result of the occurrence of defective fibrils in addition to classic fibrils. This twocompartment model leads to polymerising constant values, $\mathrm{k}_{\mathrm{on}}$, from $4.10^{8}$ up to $4.10^{12}$ mol. $L^{-1} \cdot \mathrm{min}^{-1}$. Such a range of values for polymerising constants (also named in literature as association rate constants, $\mathrm{k}_{\mathrm{on}}, k_{a}$ or $\left.k_{+}\right)$is commonly encountered in other examples of protein-protein associations (aggregation) when fast polymerising constants are involved [8]. On the other hand, the depolymerising constant values $\left(\mathrm{k}_{\mathrm{dep}}\right.$ from $2.10^{3}$ up to $2.10^{7} \mathrm{~min}^{-1}$ ) are representative for a very high dissociation rate constant which, although rare, as they are usually lower than $1 \mathrm{~min}^{-1}$, can be encountered for another aggregating protein, tubulin [4]. For a better modulation of slopes and heights, an additional assumption could be added to the two-compartment model such as a progressive formation of a defective fibril by more than only one monomer. Recent experimental observations from our collaborating team are indeed in favor of such a complementary hypothesis for explaining the kinetics of prion fibrils.

\section{REFERENCES}

[1] J. M. Ball and J. Carr and O. Penrose, The Becker-Döring cluster equations: Basic properties and asymptotic behaviour of solutions, Commun. Math. Phys., 104: 657-692, 1986

[2] R. Becker and W. Döring, Ann. Phys, 416: 719-752, 1935

[3] F.P.Da Costa,Asymptotic behaviour of low density solutions to the generalized Becker-Döring equations, NoDEA Nonlinear Differential Equations Appl.,5: 23-37,1998

[4] M. Gardner, B. Charlebois, I. Jánosi, J. Howard, A. Hunt, and D. Odde, Rapid Microtubule Self-Assembly Kinetics, Cell, 146: 582-592, 2011

[5] B. Niethammer. On the Evolution of Large Clusters in the Becker-Döring Model, J. Nonlinear Sci., 13:115-122, 2003

[6] M. Polymenidou and D. Cleveland, Prion-like spread of protein aggregates in neurodegeneration, J. Exp. Med., 209 : 889-893, 2012

[7] S. Prigent and D. Martin, C. Sizuin, V. Beringue, A. Igel-Egalon, P. Marchand, G. van der Rest, C. Malosse, M. Adrover, M. van Audenhaege, C. Chapuis, J. Torrent and H. Rezaei, Molecular basis of structural information transference during prion conversion, paper in preparation

[8] H.-X. Zhou and P. A. Bates, Modeling protein association mechanisms and kinetics, Curr. Opin. Struct. Biol., 23:1-7, 2013 